\title{
ASSESMENT OF THE QUALITY OF METAMORPHIC AND IGNEOUS ROCKS FROM TERPNI (SERRES, NORTH GREECE) FOR THEIR USE AS RAW MATERIALS IN THE PRODUCTION OF STONEWOOL
}

\section{Lampropoulou P. ${ }^{1}$, Papoulis D. ${ }^{1}$, Metaxa E. ${ }^{1}$, Tsikouras B. ${ }^{2}$, Hatzipanagioutou K. ${ }^{1}$, Tzevelekou Th. $^{3}$ and Karageorgis A. ${ }^{3}$}

${ }^{1}$ University of Patras, Department of Geology, Section of Earth Materials, 265 04, Patras, Greece, p.lampropoulou@upatras.gr,papoulis@upatras.gr,eygenia1990_@hotmail.com, k.hatzipanagiotou@upatras.gr

${ }^{2}$ University of Brunei Darussalam, Faculty of Science, Physical and Geological Sciences, JalanTungku Link, Gadong BE1410, Bandar Seri Begawan, Brunei Darussalam,basilios.tsikouras@ubd.edu.bn

${ }^{3}$ Hellenic Research Centre for Metals S.A. (ELKEME), 56th km Athens - Lamia National Road, 32011 OinofytaViotias, Greece,ftzevelekou@elkeme.vionet.gr, akarageorgis@elkeme.vionet.gr

\begin{abstract}
Metamorphic and igneous rocks of Terpnis' Serres in N. Greece have been studied. Nowadays these metamorphic rocks are used as raw materials in stone wool production, by Fibran industry, whilst the studied plutonic samples with lower content of iron oxide are proposed as alternative raw material for the production of new lightly colored stone wool, according to the market demands.

Selected epidote amphibolites and quartz diorite samples were analyzed by ICP-OES, AAS, XRD, Petrographic microscopy, and SEM.

The epidote-amphibolites show some evidence of weathering leading to sericiticsaussuritizated plagioclase crystals and secondary smectite and chlorite nanocrystals. Phyllosilicates affect positively the grinding procedure and melting of the raw materials under industrial conditions of stone wool production, due to its lower hardness and melting point compared to that of the primary hornblende.

The chemical and major mineralogical composition, the heterogeneous characteristics of textures as well as the frequent presence of phyllosilicates, due to the weathering of the plutonic studied samples, are expected to contribute to the easier grinding and melting of rocks under industrial conditions as well as to the production of a new light colored and competitive stone wool product.
\end{abstract}

Keywords: thermal insulation, mineralogy, microstructure, natural stone.

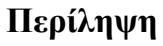

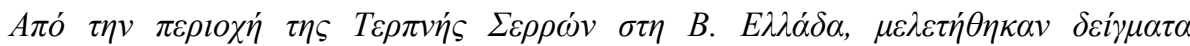

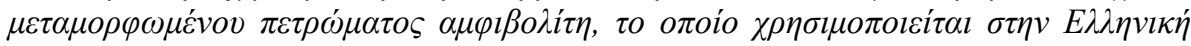

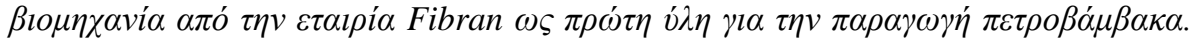

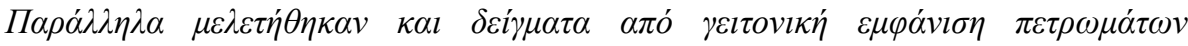

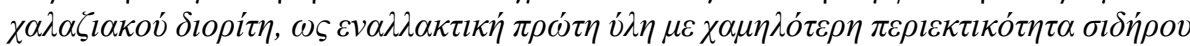




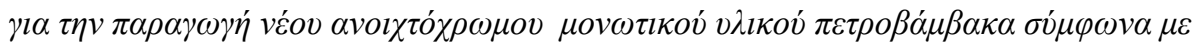
$\tau \iota \varsigma \alpha \nu \alpha \dot{\gamma} \kappa \varepsilon \varsigma \varsigma \tau \eta \varsigma \alpha \gamma o \rho \alpha ́ \varsigma$.

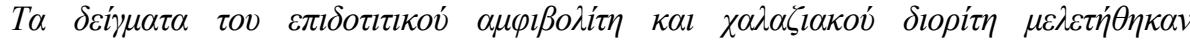

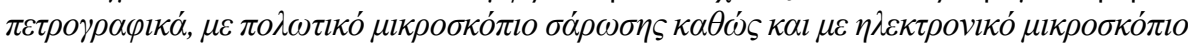

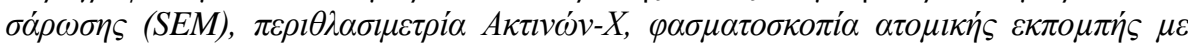

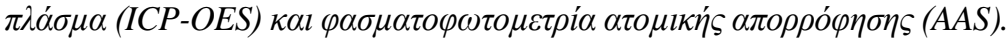

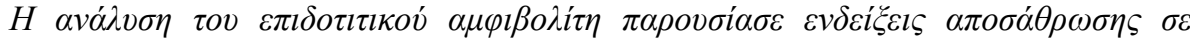

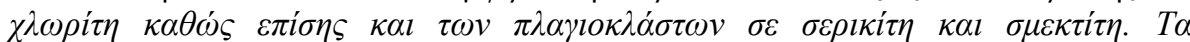

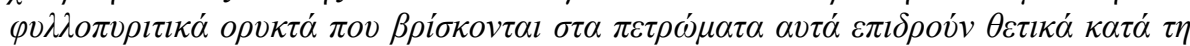

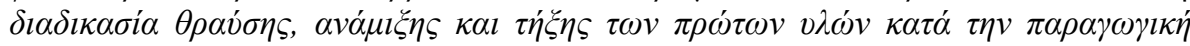

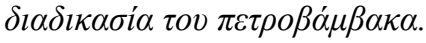

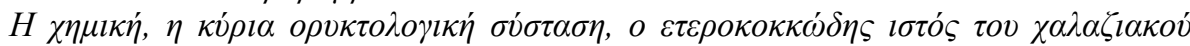

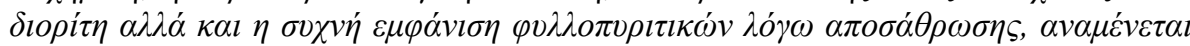

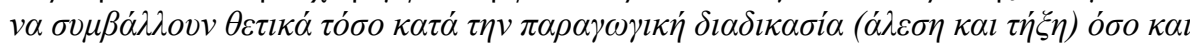

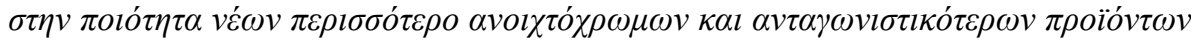
$\pi \varepsilon \tau \rho o \beta \alpha \dot{\alpha} \beta \beta \alpha \kappa$.

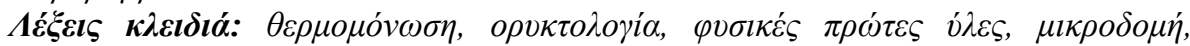

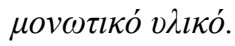

\section{Introduction}

In the middle of 19th century, in Hawaii, American geologists discovered woolen strings of stone lying on the ground. That was made after volcanic eruption. The inhabitants used them to reinforce their homes and called them Pele's hair.

Stone wool consists of fibers with an average length of $4-20 \mu \mathrm{m}$, are inflamed and derive from rock melting at $1450-1600^{\circ} \mathrm{C}$ (Blagojevic et al., 2004; Ecofys, 2012). Their chemical composition is dominated by the presence of aluminum-silicon oxides and their colour is amber.

The most important use of stone wool is in construction, because it exhibits insulation's unique fireretardant properties (Karamanos et al., 2004; Karamanos et al., 2005), sound absorption/insulation (Antonio et al., 2003) and water repellence. Also stone wool is well known for its external uses (in insulation, external façades and roofs (Yang and Zhang, 2012) and for bio-solubility in the body (Bomberg and Onysko, 2015). Stone wool materials are also used in industrial applications, particularly at relatively high temperatures up to $1000{ }^{\circ} \mathrm{C}$ as a casing material in furnaces and fireplaces as well as in agriculture as a substrate in hydroponic applications.

Worldwide basalts, metabasalts, diabases, gabbros, bauxites, anorthosites, limestones and carbonate minerals are used as raw material to produce mineral wool (Papadopoulos, 2005). The main chemical compounds included in the composition of these raw materials are oxides of silicon, aluminum, calcium, magnesium and iron. Greece is the only country that uses amphibolites as the major raw material.

This study aims at evaluating the quality of metamorphic and igneous rocks of Terpnis' Serres in N. Greece (Figure 1a) as raw materials in stone wool production. The relation between the mineralogical, geochemical and microstructural characteristics of these rocks, with the properties of the stone wool products as well as the production procedure were also investigated.

\section{Geological Settings}

The studied area (Terpni Serres) is located in northern Greece (Figure 1a) and belongs to the SerboMacedonian massif. The Serbo-Macedonian massif is divided into two units, the lower (Kerdilion) and the upper (Vertiskos) (Mountrakis, 2010). The main rocks of lower unit are gneisses while in the studied area they coexist with diorites, amphibolites and conglomerates (Figure 1b). 


\section{Materials and Methods}

A representative epidote amphibolitic sample and three quartz diorite samples were analyzed and studied in this work. Currently the metamorphic studied rocks are used as raw materials in the industrial production of stone wool materials by the Greek company Fibrangeo, whilst the adjacent quartz diorite rocks are studied as an alternative physical raw material. The chemical analysis of major and trace elements was conducted at the Analytical Chemistry laboratory of the Hellenic Research Centre for Metals by ICP-OES (Inductively Coupled Plasma Optical Emission Photometer) and AAS (Atomic Absorption Spectroscopy). The composition of bulk-rock mineralogy and of clay fractions $(2-20 \mu \mathrm{m})$ was determined by X-Ray powder Diffraction (Bruker, D8 Advance Diffractometer equipped with a LynxEye ${ }^{\circledR}$ detector) at the Dept. of Geology, Univ. of Patras. Conditions for the XRD analysis on bulk-rock mineralogy were $\mathrm{CuK} \alpha$ radiation $(40 \mathrm{kV}$ and $40 \mathrm{~mA}$ ), in the range $2-70^{\circ} 2 \theta$, with a scanning angle step of $0.015^{\circ}$ and a time step of $0.3 \mathrm{~s}$. For the identification of clay minerals standard procedures have been applied, oriented samples of the $<20 \mu \mathrm{m}$ size-fractions extracted by sedimentation, in the air-dried state and after ethylene glycol solvation was used. The mineral phases were detected using the DIFFRACplus EVA ${ }^{\circledR}$ software (Bruker-AXS, USA) based on the ICDD Powder Diffraction File. Petrographic, fabric and microstructure observations were performed on polished thin sections and fracture surfaces, using a Leica DM LSP polarizing microscope equipped with a digital imaging system (at the Dept. of Geology, Univ. of Patras) and Scanning Electron Microscope equipped with an Energy Dispersive Spectrometer (EDS) (SEM JEOL 6300 at the Laboratory of the Electron Microscopy and Microanalysis, Univ. of Patras and LEO SUPRA 3VP at the Institute of Chemical Engineering Sciences (ICE-HT), Patras), respectively.

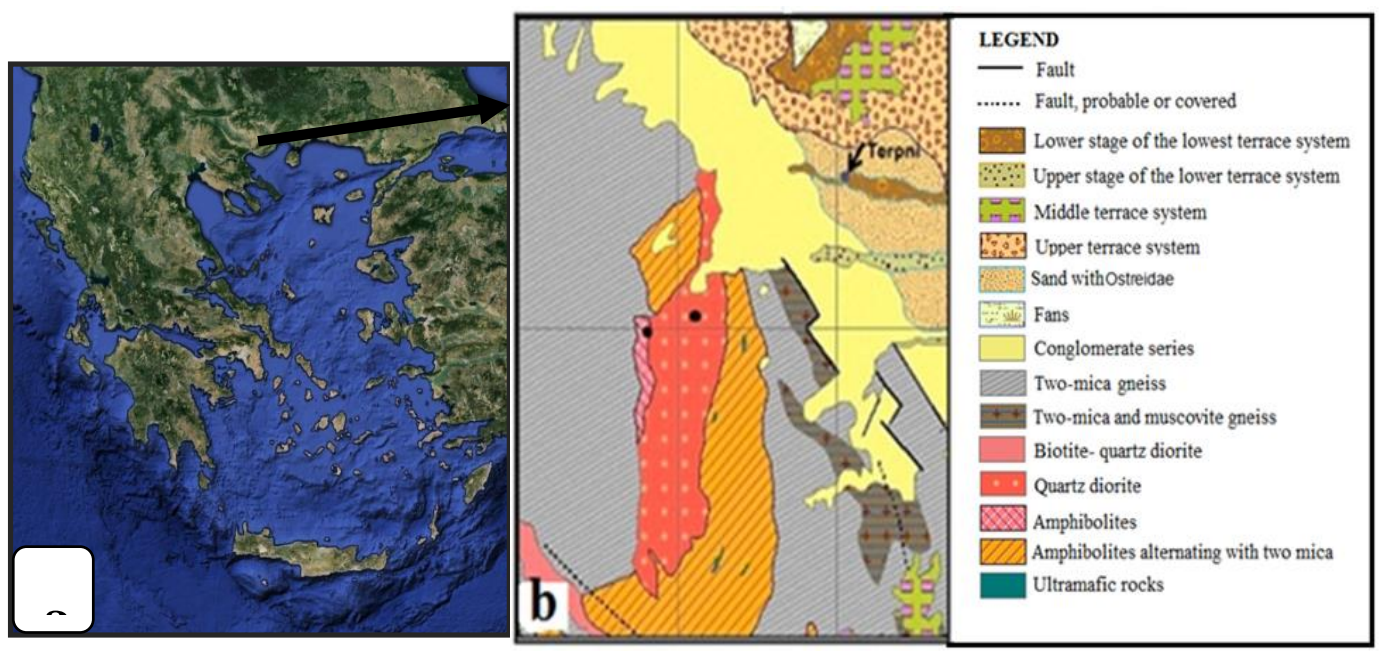

Figure 1 - (a) Map of the Greece area, (b) Modified geological map by GIS from the issue of IGME "SOHOS". The black dots show the sampling points, amphibolitic (left) and quartz diorite (right) rocks.

\section{Results and discussion}

\subsection{Chemistry}

Representative chemical analyses of studied epidote amphibolitic and quartz dioritic rocks are presented in Table 1. The igneous rocks showed lower contents of iron, calcium and magnesium oxides and higher content of silicon oxide than those in the metamorphic ones. According to the industrial market demands for light colored stone wool products, the lower content of iron in the latter rocks was the first criterion for studying these as alternative raw materials. 
Table 1 - Representative chemical analyses of studied samples (ICP-OES).

\begin{tabular}{|l|c|c|}
\hline \multicolumn{1}{|c|}{ Sample } & Epidote amphibolitic rock & Quartz dioritic rock \\
\hline$\% \mathrm{wt}$ oxides & & \\
\hline $\mathrm{SiO}_{2}$ & 49.14 & 63.79 \\
\hline $\mathrm{TiO}_{2}$ & 1.98 & 0.44 \\
\hline $\mathrm{Al}_{2} \mathrm{O}_{3}$ & 13.71 & 13.83 \\
\hline $\mathrm{Fe}_{2} \mathrm{O}_{3}$ & 12.07 & 6.48 \\
\hline $\mathrm{MnO}$ & 0.13 & 0.06 \\
\hline $\mathrm{MgO}$ & 5.98 & 2.71 \\
\hline $\mathrm{CaO}$ & 11.71 & 4.83 \\
\hline $\mathrm{Na}{ }_{2} \mathrm{O}$ & 2.03 & 2.25 \\
\hline $\mathrm{K} 2 \mathrm{O}$ & 0.59 & 1.53 \\
\hline $\mathrm{LOI}$ & 2.66 & 4.06 \\
\hline $\mathrm{Total}$ & 100.01 & 99.97 \\
\hline
\end{tabular}

\subsection{Mineralogy and Microstructure}

The major mineral phases of the epidote amphibolitic rock (S1) that were detected are magnesiohornblende (Figure 2), feldspar (oligoclase and Na feldspar, Figure 3) and epidote. In some cases it shows evidence of weathering (and probably hydrothermal alteration also) leading to sericitic-saussuritizated plagioclase crystals and secondary smectite or rarely chlorite nanocrystals (Figures 4, 5, 6). Due to the large available space for the growth of clay minerals, the orientation of clay particles is random and the rock's porosity high (Keller, 1978), as it is evident by clay minerals morphology. The rock's texture is characterized by fine grained inoblastic hornblende and granoblastic feldspars (Figure 5).

The mineralogical compositions as well as the microstructural characteristics of the studied plutonic samples (quartz diorite rocks) (Figures 4, 7, 8), revealed the presence of some unaffected rocks (S2) as well as low to medium altered ones (S3) and highly altered samples (S4) after weathering (Velde, 1995; Meunier, 2005). Biotite, hornblende and plagioclase are dominant in unaffected rocks. Deficient secondary chlorite nanocrystals, smectite and cauliflower hematite are present in the slightly and medium altered rocks, whilst well formed chlorite nanocrystals as rosettes occur in the completely altered rocks (Figure 8). S2 sample contains oligoclase and andesine plagioclase which are substituted by albite as they are altered (S3, S4, Figure 3). The amphibole in the quartz diorite samples is characterized as magnesio- hornblende (Figure 2). Several microanalyses of secondary chlorite revealed the occurrence of pycnochlorite in sample S2, while diabantite seems to be dominant in the chemically affected samples (S4). The texture of these specimens could be characterized as dissimilar coarse to medium grained. 


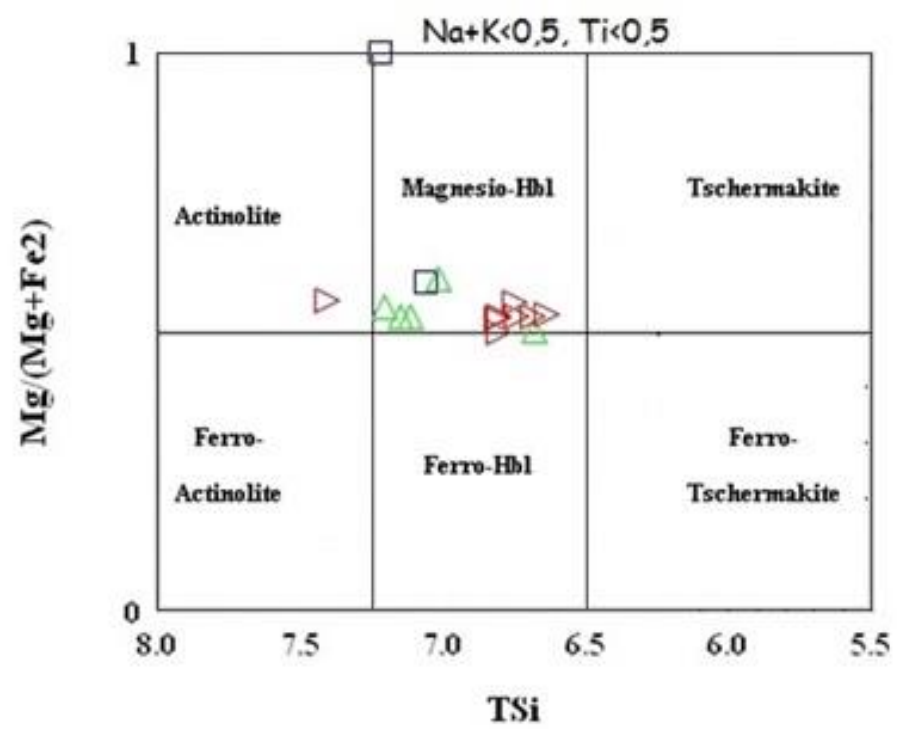

Figure 2 - Chemical classification diagram for the amphiboles (Leake et al., 1997) Legend: $\triangleright$ : Epidote amphibolitic rock, $\Delta$ : Quartz diorite rock, $\square$ : Altered Quartz diorite.

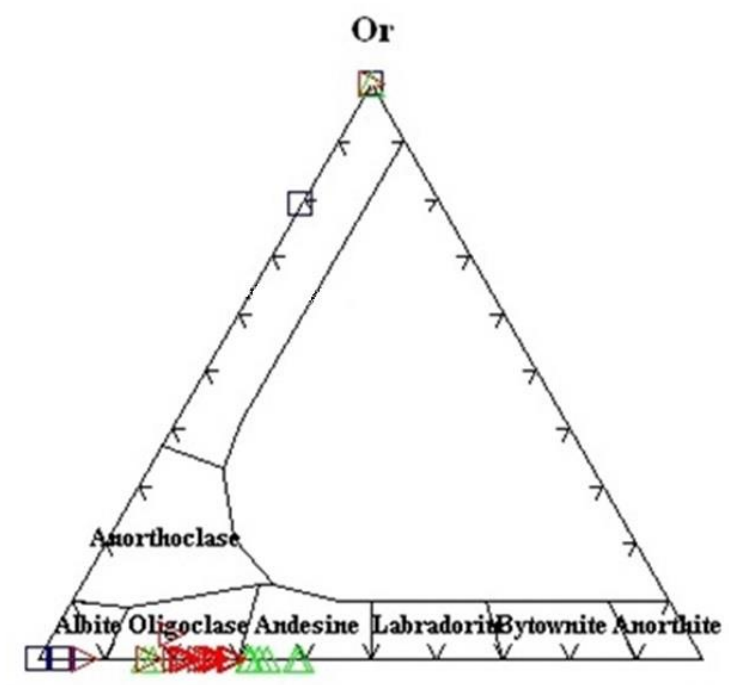

Ab

An

Figure 3 - Chemical classification diagram for the plagioclase in epidote amphibolitic and quartz diorite rock. Legend: $\gg$ : Epidote amphibolitic rock, $\Delta$ : Quartz diorite rock, $\square$ : Altered Quartz diorite. 


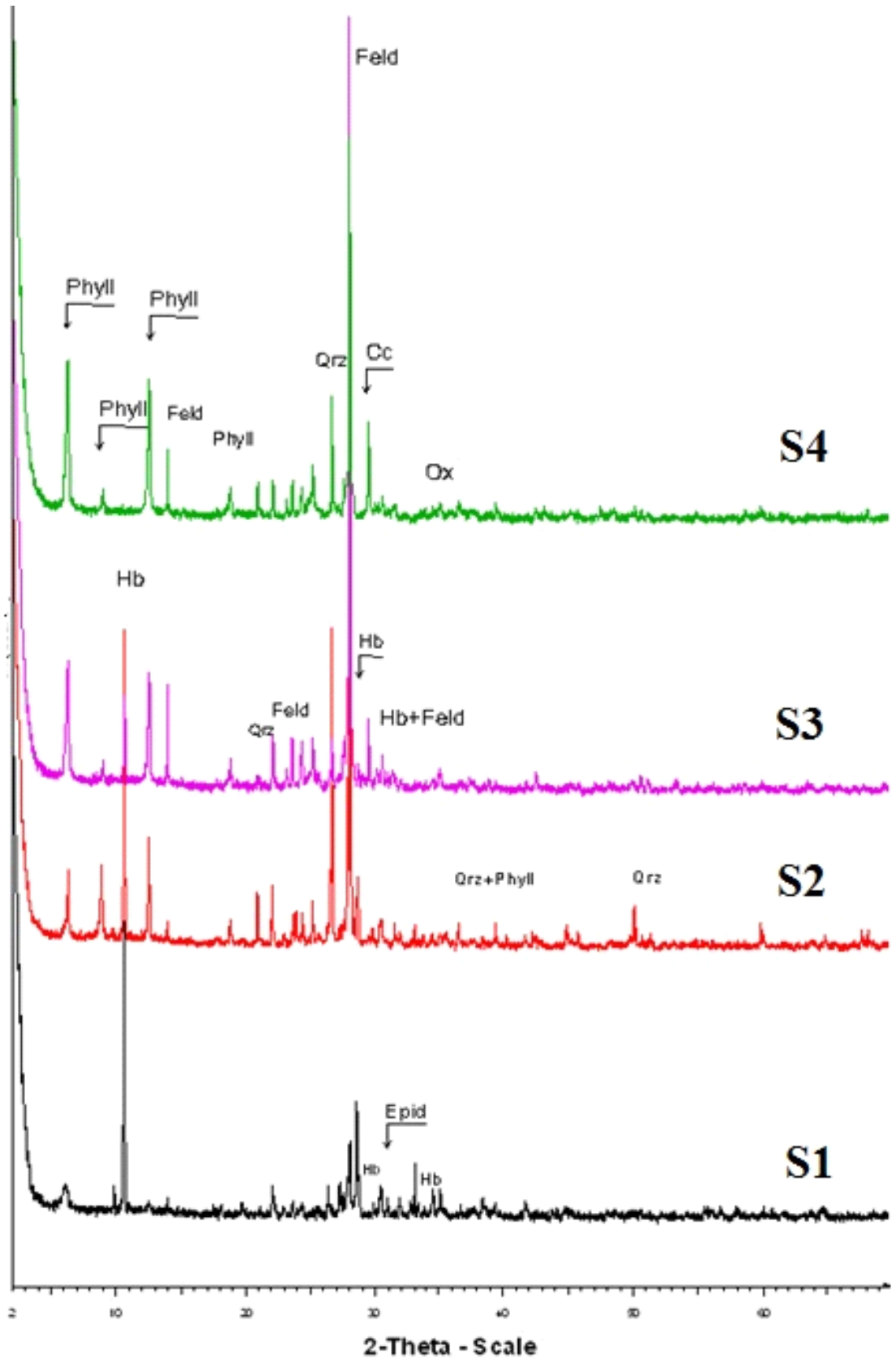




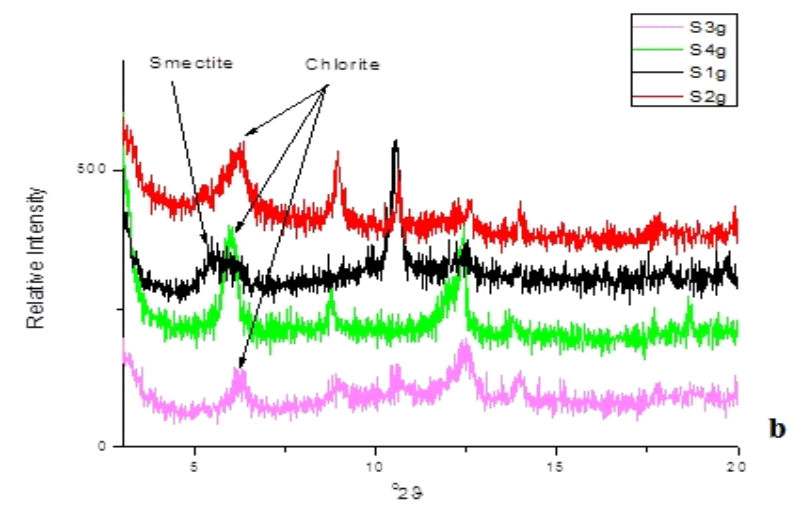

Figure 4 - (a) X-ray diffraction patterns of bulk studied samples. feldspar (Feld), phyllosilicates (Phyll), hornblende (Hb), epidote (Ep), quartz (Qrz), calcite (Cc), oxides (Ox), (b) X-ray patterns of clay fraction of the studied samples (S1-4) after ethylene-glycol treatment (g). S1: Epidote amphibolitic rock; S2: Unaffected Quartz diorite rock; S3: Medium altered Quartz diorite rock; S4: Highly altered Quartz diorite rock.
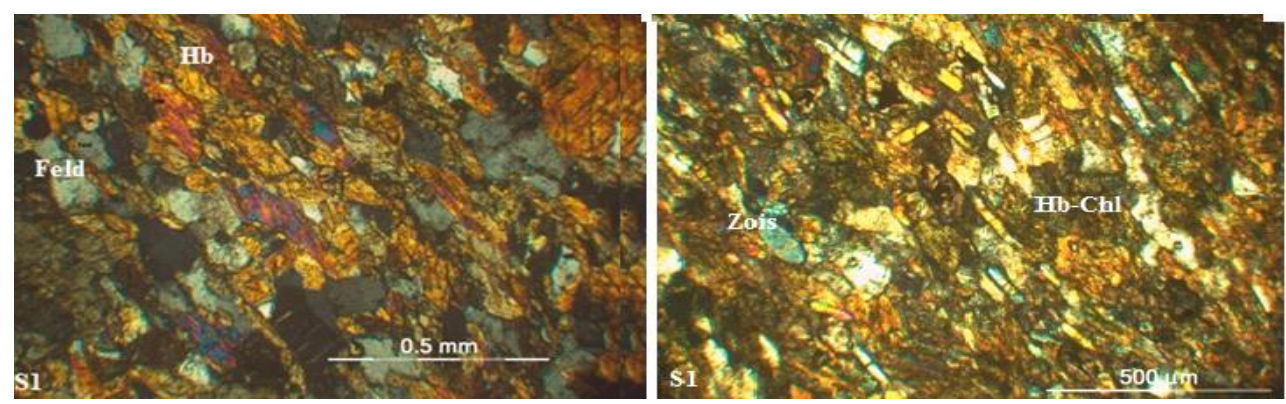

Figure 5 - Photomicrographs in crossed polars (XPL) of S1 sample showing the presence of feldspar (Feld), hornblende (Hb), zoisite (Zois) and chlorite (Chl).
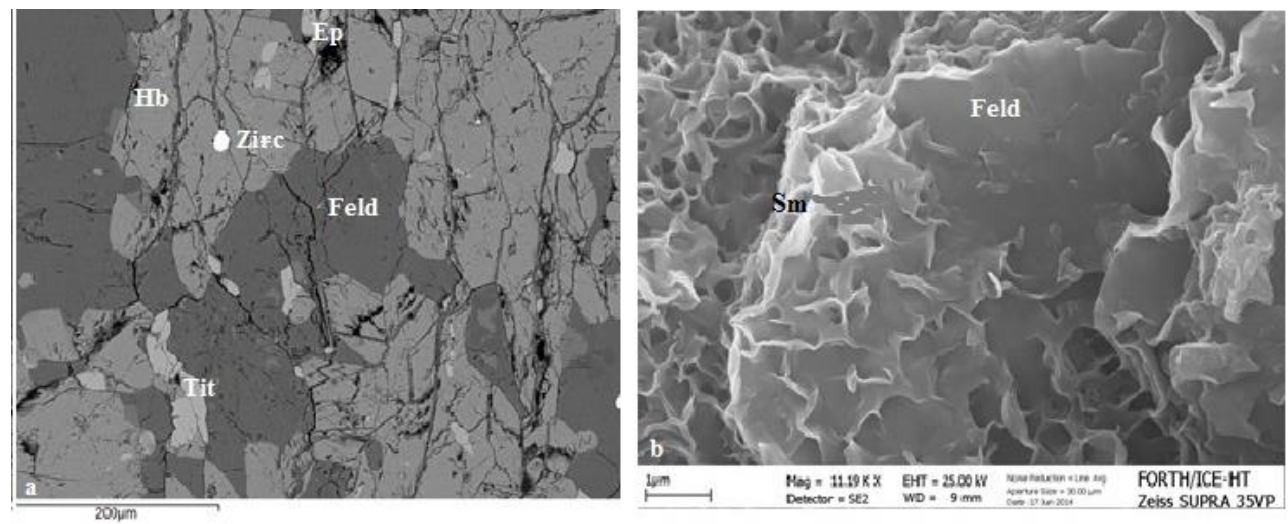

Figure 6 - (a) Backscattered electron image of the epidote amphibolitic rock microstructure (S1) and (b) secondary electron image on fracture surface of S1 sample showing a feldspar surface altered to smectite flakes. feldspar (Feld), hornblende (Hb), epidote (Ep), zircon

(Zirc), titanite (Tit), smectite (Sm). 

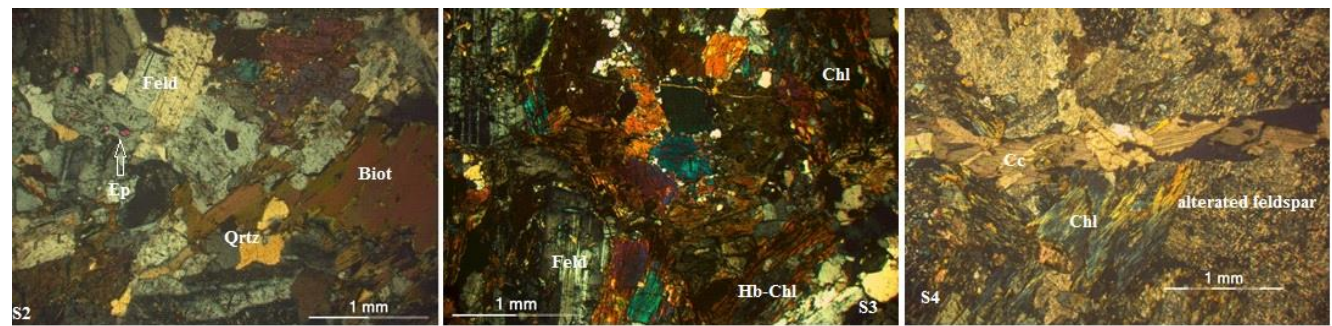

Figure 7 - Photomicrographs in crossed polars (XPL) of S2, S3, S4 microstructures. feldspar (Feld), hornblende (Hb), biotite (Biot), epidote (Ep), quartz (Qrtz), chlorite (Chl), calcite (Cc).

The typical industrial mixture of the raw materials (epidote amphibolitic rock, bauxite, lime and dolomite) that is currently implemented by FIBRAN in the production of advanced stone wool materials, demands a specific chemical composition (Table 2). The fine grained texture and the major mineralogical composition of quartz diorite rocks in combination with the presence of smectite and chlorite (with lower hardness and melting point than that of the primary hornblende) promote the grinding procedure and melting of raw materials under industrial conditions.

The results of the studied plutonic rocks revealed that these materials do not vary significantly in chemical and mineralogical composition from the metamorphic ones. So the addition of an appropriate ratio of quarz dioritic rock instead of epidote-amphibolitic could lead to a new prepared mixture of raw materials with a lower $\mathrm{FeO}$ content, preserving simultaneously the standard industrial recipe (Table 2). Furthermore, the dissimilar coarse to medium grained texture in these specimens (S2, S3, S4) as well as the presence of chlorite nanocrystals and other secondary clay minerals anticipate for the easier grinding and melting of rocks. According to the above, these igneous rocks could be tested in a pilot laboratory scale as an alternative raw material for the production of new, light-colored and global competitive stone wool with no increase of industrial economy cost.

Table 2 - Typical industrial major chemical composition of raw materials mixture for stone wool production.

\begin{tabular}{|l|l|}
\hline \multicolumn{1}{|c|}{ Oxides } & \multicolumn{1}{c|}{ \%wt } \\
\hline $\mathrm{SiO}_{2}$ & -37 \\
\hline $\mathrm{CaO}+\mathrm{MgO}$ & 26 \\
\hline $\mathrm{Al}_{2} \mathrm{O}_{3}$ & 18 \\
\hline $\mathrm{FeO}_{\mathrm{x}}$ & $-6-11$ \\
\hline
\end{tabular}



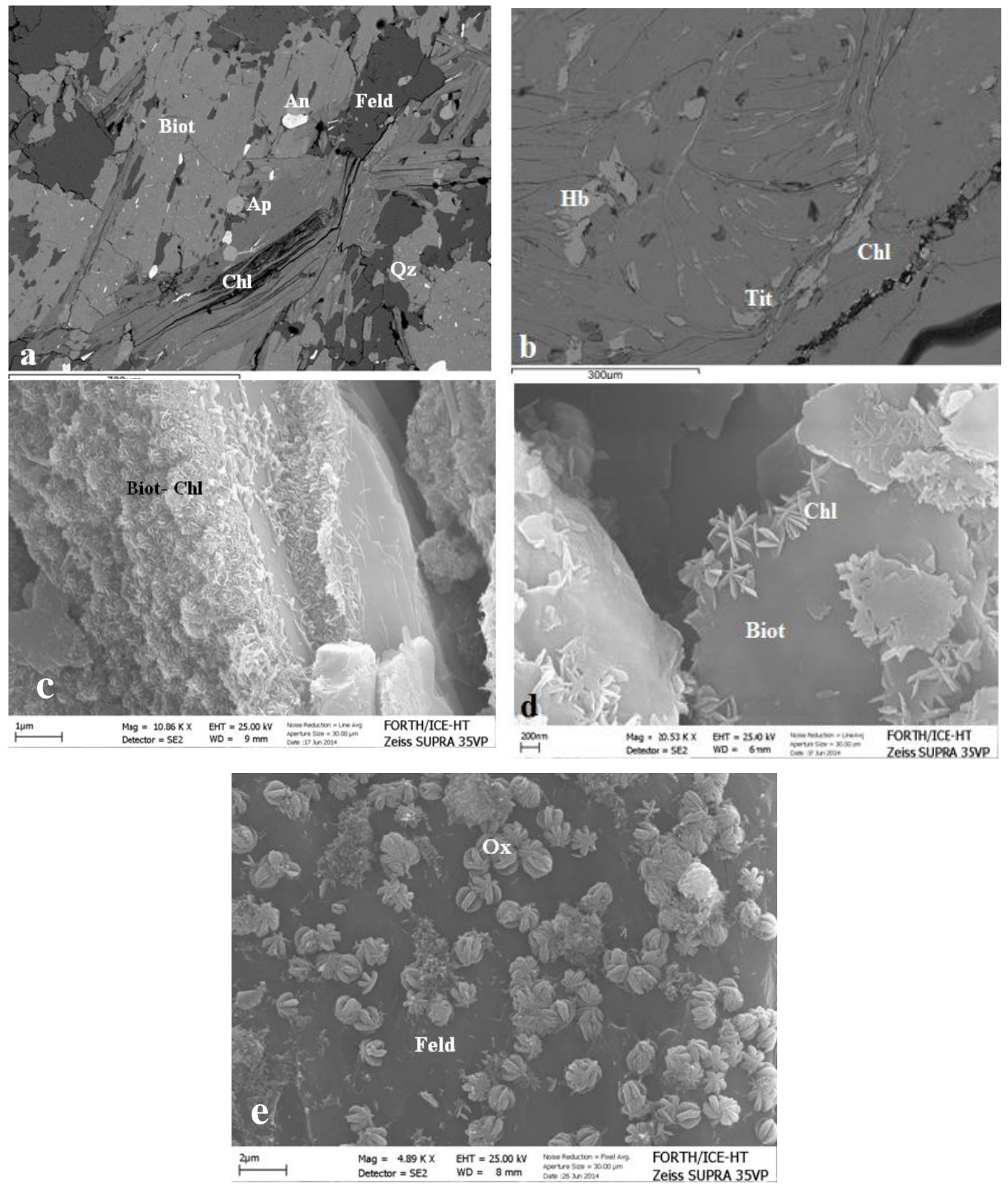

Figure 8 - (a) and (b) Representative backscattered electron images of S2 and S4 microstructures, respectively; (c) Secondary electron image on fracture surface of S2 sample: Biotite altered to chlorite; (d) Magnification of Figure 8 (c); (e) cauliflower hematite on feldspar surface in S4 sample feldspar (Feld), hornblende (Hb), biotite (Biot), chlorite (Chl), quartz (Qrz), anatase (An), titanite (Tit), apatite (Ap), oxides (Ox) (cauliflower hematite).

\section{Conclusions}

- The metamorphic rocks consist of magnesiohornblende, feldspar (oligoclase and Nafeldspar) and epidote in a fine grained inoblastic to granoblastic texture. Low amounts of secondary smectite and nano-chlorite crystals due to weathering are also detected. 
- Biotite, magnesiohornblende and plagioclase (oligoclase and andesine) are mainly detected in unaffected plutonic studied samples. Biotite and magnesiohornblende are almost absent in the altered rocks while deficient secondary chlorite nanocrystals, smectite and cauliflower hematite are present.

- The presence of secondary phyllosilicates in both studied metamorphic and igneous rocks is expected to affect positively the industrial production processes of stone wool.

- The quartz diorite rocks are proposed as an alternative raw material in the production of new, light-colored and advanced stone wool materials.

\section{Acknowledgments}

We would like to thank E. Kotsopoulou from the laboratory of Electron Microscopy and Microanalysis, University of Patras and V. Drakopoulos from Institute of Chemical Engineering Sciences (ICE-HT), Patras, for his assistance with the EDS microanalyses and SEM photomicrographs. Special thanks to Fibran industry for their collaboration Rock.FeNi.Al research project "914-BET2013", supported and funded by the Development Program for Industrial Research and Technology PAVET 2013, ESPA 2007-2013, European Regional Development Fund ERDF. The authors would also like to thank anonymous Reviewer for helping improving our manuscript.

\section{References}

Blagojevic, B., Sirok, B. and Stemfelj, B., 2004. Simulation of the effect of melt composition on mineral wool fibre thickness, Ceramics-Silikaty, 48(3).

Bomberg, M. and Onysko, D., 2015. Walls of Canadian Houses: A Review of the Historic Basis for Current Practices, Journal of Building Physics, EE9-1 Innovative Materials: Bio-Fiber Batts and Boards.

Ecofys/Fraunhofer, 2012. Methodology for the free allocation of emission allowances in the EU E TS post 2012, Sector report for the mineral wool industry, By order of the European Comm is-sion, Institute for Systems and Innovation Research, Oko-Institut, $20 \mathrm{pp}$.

Antonio, J.M.P., Tadeu, A. and Godinho, L., 2003. Analytical evaluation of the acoustic insulation provided by double infinite walls, 114-129.

Karamanos, A., Papadopoulos, A. and Anastasellos D., 2004. Heat transfer phenomena in fibrous i nsulating materials Laboratory of Heat Transfer and Environmental Engineering, Departme nt of Mechanical Engineering Aristotle University Thessaloniki, 26 pp.

Leake, B.E., Woolley, A.R., Arps, C.E.S., Birch, W.D., Gilbert, M.C., Grice, J.D., Hawthorne, F.C., Kato, A., Kisch, H.J., Krivovichev, V.G., Linthout, K., Laird, J., Mandarino, J., Maresch, W.V., Nickel, E.H., Rock, N.M.S., Schumacher, J.C., Smith, D.C., Stephenson, N.C.N., Ungaretti, L., Whittaker, E.J.W. and Youzhi, G., 1997. Nomenclature of amphiboles: report of the subcommittee on amphiboles of the International Mineralogical Association Commision on new minerals and mineral names, Min. Mag., 61, 295-321.

Meunier, A., 2005. Clays, Springer-Verlag Berlin Heideblberg 2005.

Mountrakis, D., 2010. Geology and tectonic evolution of Greece, University Studio Press, 2010.

Velde, B., 1995. Origin and Mineralogy of Clays, Springer-Verlag Berlin Heideblberg 1995.

Yang, S. and Zhang, L., 2012. Research on Properties of Rock- Mineral Wool as ThermalInsulation Material for Construction.

Karamanos, A., Papadopoulos, A. and Anastasellos, D., 2005. Comparative Evaluation of stonewool and extruded Polystyrene, Department of Mechanical Engineering, Aristotle Uni versity Thessaloniki, $11 \mathrm{pp}$.

Keller, W.D., 1978. Classification of kaolins exemplified by their textures in scan electron micrographs, Clays and Clay Minerals, 26, 1-20.

Papadopoulos, A.M., 2005. State of the art in thermal insulation materials and aims for future developments, Energy and Buildings, 37, 77-86. 